\title{
Effect of 15\% Carbamide Peroxide on the Surface Roughness and Adhesion of Streptococcus mutans to Microhybrid Composite Resin and Giomer
}

\author{
${ }^{1}$ Narmin Mohammadi, ${ }^{2}$ Shadieh Mowlaie, ${ }^{3}$ Siavash Savadi-Oskoee, ${ }^{4}$ Mohammad E Ebrahimi \\ ${ }^{5}$ Sahand Rikhtegaran, ${ }^{6}$ Mahdi Rahbar, ${ }^{7}$ Tahereh Pirzadeh
}

\begin{abstract}
Introduction: Adhesion of bacteria, especially Streptococcus mutans (S. mutans), to the surface of tooth restorations is a factor in the etiology of secondary caries. Given the ever-increasing popularity of bleaching procedures, the aim of the present study was to evaluate adhesion of $S$. mutans and surface roughness (SR) of microhybrid composite resin and giomer subsequent to the application of $15 \%$ carbamide peroxide.
\end{abstract}

Materials and methods: Twenty disk-shaped samples were prepared from each material, measuring $8 \mathrm{~mm}$ in diameter and $2 \mathrm{~mm}$ in thickness. Then, the samples of each material were divided into two groups $(n=10)$ : (a) microhybrid without bleaching; (b) microhybrid with bleaching; and (c) giomer without bleaching; and (d) giomer with bleaching. The samples in groups I and III were immersed in artificial saliva for 14 days without any bleaching procedure; the samples in groups II and IV underwent a bleaching procedure on their polished surfaces with $15 \%$ carbamide peroxide for 14 days (4 hours of bleaching and 20 hours of immersion in artificial saliva). The SR of all the samples was determined with the use of a profilometer. The samples were added to the culture medium after 4 hours of placement in a microbial suspension at $37^{\circ} \mathrm{C}$; after 24 hours of incubation at $37^{\circ} \mathrm{C}$, the bacterial counts, indicating the number of bacteria adhering to the surface, were determined by counting them in the plates containing the solid culture medium.

Results: The type of the restorative material had a significant effect on SR, with greater SR in giomer $(p=0.03)$. However, bleaching had no significant effect on $S R(p=0.099)$. In relation to the rate of bacterial adhesion (BA), both the types of the restorative materials and bleaching procedures were significantly effective; in this context, there was more BA in microhybrid composite resin samples that did not undergo bleaching $(p<0.001)$. Bleaching resulted in the adhesion of $S$. mutans to the surface of both materials decrease. Pearson's correlation coefficient did not reveal any correlation between BA and SR $(p=0.42)$.

\footnotetext{
1,3-6Department of Operative and Esthetic Dentistry, Faculty of Dentistry, Tabriz University of Medical Sciences, Tabriz, Islamic Republic of Iran

${ }^{2}$ Department of Operative and Esthetic Dentistry, Faculty of Dentistry, Ardabil University of Medical Science, Ardabil, Islamic Republic of Iran

${ }^{7}$ Department of Microbiology, Tabriz University of Medical Sciences, Tabriz, Islamic Republic of Iran

Corresponding Author: Shadieh Mowlaie, Department of Operative and Esthetic Dentistry, Faculty of Dentistry, Ardabil University of Medical Science, Ardabil, Islamic Republic of Iran Phone: +9143523034, e-mail: Sh.mowlaie@gmail.com
}

Conclusion: The BA was higher in microhybrid composite resin, and SR was higher in giomer. The BA was higher in samples that did not undergo a bleaching procedure.

Clinical significance: There is no change in the SR of microhybrid composite resin and giomer after application of $15 \%$ carbamide peroxide; therefore, it is not necessary to polish or replace these restorative materials after bleaching. In addition, use of $15 \%$ carbamide peroxide does not increase caries risk.

Keywords: Carbamide peroxide, Giomer, Microhybrid composite resin, Streptococcus mutans, Surface roughness.

How to cite this article: Mohammadi N, Mowlaie S, SavadiOskoee S, Ebrahimi ME, Rikhtegaran S, Rahbar M, Pirzadeh T. Effect of $15 \%$ Carbamide Peroxide on the Surface Roughness and Adhesion of Streptococcus mutans to Microhybrid Composite Resin and Giomer. World J Dent 2017;8(4):288-295.

Source of support: Nil

Conflict of interest: None

\section{INTRODUCTION}

Discolored vital teeth are treated in different ways to improve their esthetic appearance, including the use of crowns, direct and indirect veneers, composite resin restorations, and bleaching, which is the most conservative technique. ${ }^{1}$ At-home bleaching is the most commonly recommended treatment modality for vital teeth. ${ }^{2}$ However, these teeth might have tooth-colored restorations. The clinical longevity of tooth-colored restorations might be affected by chemical processes of bleaching agents. ${ }^{3}$ The effects of bleaching agents include changes in surface morphology and in the physical and chemical properties of tooth-colored restorative materials. ${ }^{3}$ In addition, it has been shown that the SR of composite resins is affected to a great extent by bleaching procedures. ${ }^{1}$ It appears bleaching agents increase the adhesion of cariogenic bacteria to the external surfaces of dental materials. ${ }^{4}$ Adhesion of bacteria to the surfaces of composite resins and other restorative materials is a factor in the etiology of recurrent caries. ${ }^{5}$ Adhesion of $S$. mutans has the strongest correlation with caries experience. ${ }^{6}$

Composite resins are direct restorative materials that meet, in the best way, the requirements of the preservation of tooth structure, high esthetic appearance, and 
longevity. ${ }^{7}$ At present, microhybrids are the most commonly used direct restorative materials used, and in all the cases, in which a composite resin with high polishability and good mechanical properties is required, microhybrid composite resins are recommended; in fact, microhybrid composite resins are considered all-purpose universal composite resins., ${ }^{7,8}$ Based on the results of recent clinical studies, giomer, too, is a suitable restorative material for carious teeth in areas in which esthetic appearance is very important. ${ }^{9}$ The giomer technology relies on prepared glass-ionomer, which is placed as an additional phase within composite resin. ${ }^{10,11}$ In patients with poor oral hygiene and a cariogenic diet, giomer might be a good choice for decreasing the effects of a poor oral environment due to its capacity to release fluoride and high polishability. ${ }^{12,13}$ Recently, controversies have risen over the effect of bleaching agents on the physical and chemical properties of restorative materials. Two studies have shown that highly polished composite resin restorations possibly exhibit less bacterial accumulation. In contrast, Yamuchi et $\mathrm{al}^{14}$ showed that $S$. mutans exhibits greater adhesion to smooth surfaces, while Yamamoto et $\mathrm{al}^{15}$ reported no relationship between SR of composite resins and BA. Mor et $\mathrm{al}^{4}$ too showed that $S$. mutans has a higher capacity to adhere to bleached composite resin surfaces. Kimyai et $\mathrm{al}^{16}$ showed that adhesion of S. mutans to giomer is less than that to composite resin. Some studies have shown that the adhesion of $S$. mutans is higher to bleached enamel surface. ${ }^{17-19}$ However, in relation to the SR of bleached enamel, both an increase ${ }^{17}$ and absence of any change ${ }^{18}$ have been reported. In relation to the effect of bleaching on SR of restorative materials, too, contradictory results have been reported. Some studies have shown that SR of microhybrid composite resins does not noticeably change after bleaching. ${ }^{20,21}$ In addition, some studies have shown that SR of restorative materials increases after bleaching with carbamide peroxide. ${ }^{22-26}$ Mohammadi et al, ${ }^{27}$ too, showed a statistically significant difference in the SR of giomer before and after bleaching with carbamide peroxide. Since no studies are available on the adhesion of $S$. mutans to microhybrid composite resins, as they are the most commonly used tooth-colored restorative material, and giomer, which has antibacterial effects, after bleaching procedures, and considering the discrepancies in relation to the SR of these materials after bleaching, the present study was designed to evaluate the effect of $15 \%$ carbamide peroxide and the material type on the adhesion of $S$. mutans and SR of these materials. The null hypotheses tested were as follows: (1) There is no difference in the SR of the study groups. (2) There is no difference in the SR of the study groups before and after bleaching. (3) The type of the restorative material and bleaching agent have no effect on the adhesion of $S$. mutans. (4) There is no correlation between the adhesion of $S$. mutans and SR of the materials.

\section{MATERIALS AND METHODS}

The protocol of the study was approved by the Ethics Committee of Tabriz University of Medical Sciences under the code IR.TBZMED.REC.1395.526. Based on the results of a pilot study and by considering a difference of 204 units in the BA variable between the two groups, with and without bleaching with standard deviations of 150.68 and 122.76 respectively, and by considering $\alpha=0.05$ and a study power of $80 \%$, the sample size was estimated at $n=8$ in each group; however, to increase the validity of the study, 10 samples were included in each group. Therefore, a total of 40 samples (10 in each group) were evaluated in this study. Four extra samples (one from each group) were included as controls.

A total of 20 disk-shaped samples were prepared within cylindrical plastic molds from microhybrid composite resin (Filtek Z250 ${ }^{\mathrm{TM}}$, 3M ESPE, St. Paul, Minnesota, USA) and 20 samples from giomer (Beautifil II, Shofu Dental Corporation, Osaka, Japan), measuring $8 \mathrm{~mm}$ in diameter and $2 \mathrm{~mm}$ in thickness. First, a transparent matrix band was placed on a glass slab under the mold. Composite resin was placed in 2-mm-thick layers on it, and then, a transparent matrix band was placed on it. A glass slab was placed tightly on it to achieve a smooth surface.

The samples were light-cured with a halogen lightcuring unit (Elipar 2500, 3M ESE) at a light intensity of 480 to $520 \mathrm{~W} / \mathrm{cm}^{2}$. A radiometer (Optilux, Model 100SDS, Kerr, Danbury Connecticut, USA) was used to evaluate and make sure of the intensity of curing light. The tip of the light-conducting device was placed in contact with the glass slab, and light-curing was carried out for 40 seconds from both sides. One surface of the samples was polished with Solfex disks in a low-speed handpiece in one direction in three states of moderate, fine, and superfine. ${ }^{3}$ The final thickness of the samples was checked with the use of a micrometer (Ultra Cal Mark 3 Flower Tools and Ins., Sylvac Newtown Mt, USA). After polishing, the samples were subjected to an ultrasound cleaning procedure with distilled water for 2 minutes and then immersed in $37^{\circ} \mathrm{C}$ distilled water for 24 hours. ${ }^{3}$

The samples of both materials were randomly assigned into two groups $(n=10)$ as follows:

- Group I: Microhybrid composite resin samples without bleaching

- Group II: Microhybrid composite resin samples after a home bleaching procedure with $15 \%$ carbamide peroxide

- Group III: Giomer samples without bleaching

- Group IV: Giomer samples after home bleaching with $15 \%$ carbamide peroxide. 
The samples in groups I and III were immersed in artificial saliva without any bleaching procedures. The samples in groups II and IV underwent a bleaching procedure with $15 \%$ carbamide peroxide on their polished surfaces for 14 days, consisting of 4 hours of bleaching every day, followed by 20 hours of storage in artificial saliva.

The artificial saliva was refreshed every day. The chemical composition of artificial saliva consisted of $0.04 \mathrm{mg}$ of sodium chloride, $0.4 \mathrm{mg}$ of $\mathrm{KCl}, 0.795 \mathrm{gm}$ of $\mathrm{CaCl}_{2} \cdot \mathrm{H}_{2} \mathrm{O}$, and $0.69 \mathrm{gm}$ of $\mathrm{NaH}_{2} \mathrm{PO}_{4} \cdot \mathrm{H}_{2} \mathrm{O}, 0.055 \mathrm{gm}$ of $\mathrm{Na}_{2} \mathrm{~S}_{9} . \mathrm{H}_{2} \mathrm{O}$, dissolved in $1000 \mathrm{~mL}$ of distilled water at $\mathrm{pH}=7^{3}$

The bleaching agent (Opalescence PF 15\% Carbamide Peroxide, Ultradent Products Inc., South Jordan, USA) was applied to the polished surface of each sample at a thickness of $1 \mathrm{~mm}$ for 4 hours each day; then the samples were immersed in artificial saliva at $37^{\circ} \mathrm{C}$ for 20 hours until the next round of the bleaching procedure. After 14 days, all the samples were immersed in distilled water at $37^{\circ} \mathrm{C}$ for 24 hours. ${ }^{3}$ At the end of the bleaching period, the SR of all the samples was determined with the use of a profilometer. ${ }^{9}$ In this test, the diamond rod of the instrument that measured $2 \mu \mathrm{m}$ in diameter scanned the surface at three points at a constant rate of $0.1 \mathrm{~mm} / \mathrm{s}$ using a force of $0.7 \mathrm{mN}$ and the mean $\mathrm{SR}$ was reported using a numeric value (Ra). In groups I and III, after 14 days of immersion in artificial saliva, the samples were immersed in distilled water at $37^{\circ} \mathrm{C}$. Then, the SR was determined with the use of a profilometer. Finally, the SR of all the four groups was compared.

\section{Evaluation of Adhesion of S. mutans}

Standard S. mutans bacterial species (ATCC25175), lyophilized according to the adjunctive protocol of the manufacturer (Biotechnology Research Center of Iran Scientific and Industrial Research Center), was activated in the tryptic soy broth (TSB) general culture medium and transferred onto the surface of TSB plates. Finally, a microbial suspension was prepared in $0.9 \%$ standard physiological serum from the colonies grown on TSB plates, at a concentration of $5 \times 10^{8}$ colony-forming units $/ \mathrm{mL}$ using the plate counting technique. After preparation of the test samples, each sample was subjected to the microbial suspension within sterile Falcon tubes at $37^{\circ} \mathrm{C}$ for 4 hours. After incubation, the test materials were retrieved from the Falcon tubes containing the microbial suspension, under sterile conditions and rinsed with sterile physiologic serum three times to remove nonadhering microbial cells. The samples were transferred into new sterile Falcon tubes containing 0.9 standard physiologic serum and placed in a sonicator for 6 minutes to separate bacterial cells adhering to the surface to achieve a suspension. In the next stage, the test samples were retrieved and added to the culture medium suspension. After 2 hours of suspension at $37^{\circ} \mathrm{C}$, the bacterial counts, indicating the number of bacteria adhering to the surface, were determined comparatively in the study groups by counting them in the plates containing solid culture medium. All the tests were carried out in the presence of a positive control group (a culture medium containing bacteria with no samples) and a negative control group (a culture medium without bacteria but with samples), and each test was repeated 6 times. ${ }^{16}$ Then, adhesion of S. mutans was compared between the study groups.

Data on SR and S. mutans adhesion were analyzed with descriptive statistics (means and standard deviations) and two-way analysis of variance (ANOVA). Statistical significance was defined at $\mathrm{p}<0.05$. Pearson's correlation coefficient was used to evaluate the correlation between SR and S. mutans adhesion. KolmogorovSmirnov test was used to evaluate normal distribution of data. Independent samples t-test was used to evaluate the effect of bleaching on each material separately considering the normal distribution of data.

\section{RESULTS}

Table 1 presents the descriptive data on SR and BA in the study groups in terms of the restorative material and bleaching procedure. Two-way ANOVA was used to evaluate SR and BA with and without bleaching with the use of microhybrid composite resin and giomer, based on normal distribution of data as shown by KolmogorovSmirnov test at $\mathrm{p}<0.05$.

- Based on the analyses, of all the factors evaluated (the restorative material and bleaching), only the type of the restorative material affected SR significantly $(p=0.03)$, which was higher in giomer. However, bleaching had no significant effect on SR ( $\mathrm{p}=0.68$; Graphs 1 and 2).

- In addition, based on the analyses, of all the factors evaluated (restorative material and bleaching), both the types of the restorative materials $(p=0.03)$ and bleaching ( $\mathrm{p}<0.001)$ affected BA significantly (Graphs 3 and 4).

- There was a 135-unit difference in BA in microhybrid composite resin with and without bleaching, with more BA in the group without bleaching. Based on the results of independent-samples t-test, the difference was significant $(p=0.00)$ (Table 1, Graphs 3 and 4).

- There was a 70-unit difference in BA in giomer with and without bleaching, with higher BA in the group without bleaching. Based on the results of independent-samples t-test, the difference was significant ( $\mathrm{p}=0.01$; Table 1, Graphs 3 and 4).

- Pearson's correlation coefficient did not reveal any correlation between BA and SR ( $p=0.42)$. 


\begin{tabular}{|c|c|c|c|c|c|c|}
\hline Groups & Bleaching & $n$ & Mean & Minimum & Maximum & Mean \\
\hline \multicolumn{7}{|c|}{ Microhybrid } \\
\hline \multirow[t]{2}{*}{$\mathrm{SR}$} & No & 10 & $0.08 \pm 0.01$ & 0.05 & 0.10 & 0.08 \\
\hline & Yes & 10 & $0.06 \pm 0.01$ & 0.05 & 0.10 & 0.07 \\
\hline \multirow[t]{2}{*}{ BA } & No & 10 & $250 \pm 52.54$ & 175 & 365 & 232.50 \\
\hline & Yes & 10 & $115 \pm 67.61$ & 30 & 225 & 90 \\
\hline \multicolumn{7}{|l|}{ Giomer } \\
\hline \multirow[t]{2}{*}{ SR } & No & 10 & $0.08 \pm 0.03$ & 0.01 & 0.12 & 0.10 \\
\hline & Yes & 10 & $0.10 \pm 0.02$ & 0.05 & 0.12 & 0.10 \\
\hline \multirow[t]{2}{*}{ BA } & No & 10 & $175 \pm 70.47$ & 65 & 270 & 165 \\
\hline & Yes & 10 & $105 \pm 36.59$ & 40 & 150 & 105 \\
\hline \multicolumn{7}{|l|}{ Total } \\
\hline \multirow[t]{2}{*}{ SR } & No & 20 & $0.08 \pm 0.02$ & 0.01 & 0.12 & 0.1 \\
\hline & Yes & 20 & $0.08 \pm 0.02$ & 0.05 & 0.12 & 0.07 \\
\hline \multirow[t]{2}{*}{ BA } & No & 20 & $212.5 \pm 71.69$ & 65 & 265 & 227.5 \\
\hline & Yes & 20 & $110 \pm 53.16$ & 30 & 225 & 100 \\
\hline
\end{tabular}

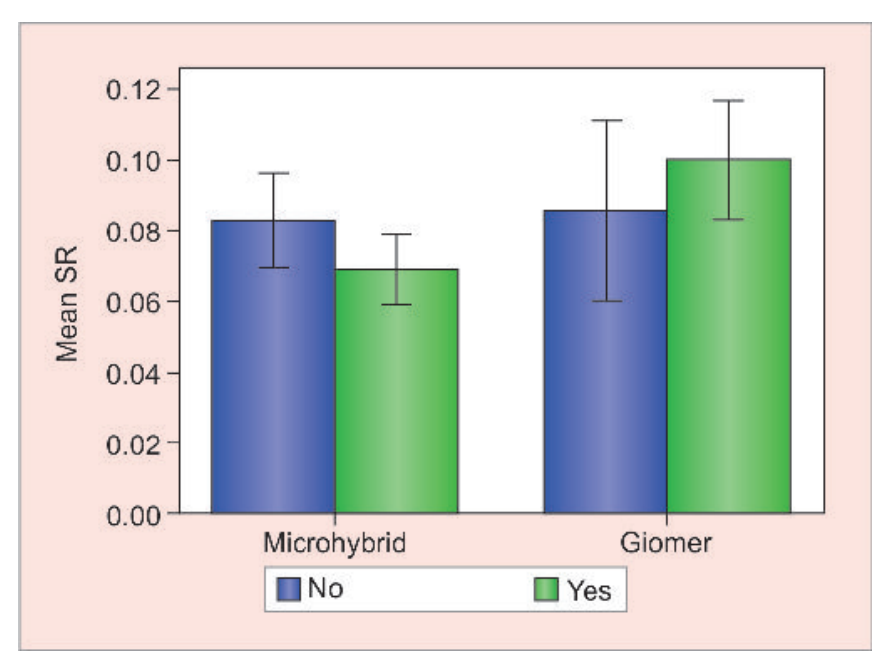

Graph 1: Mean SR based on the restorative materials of this study

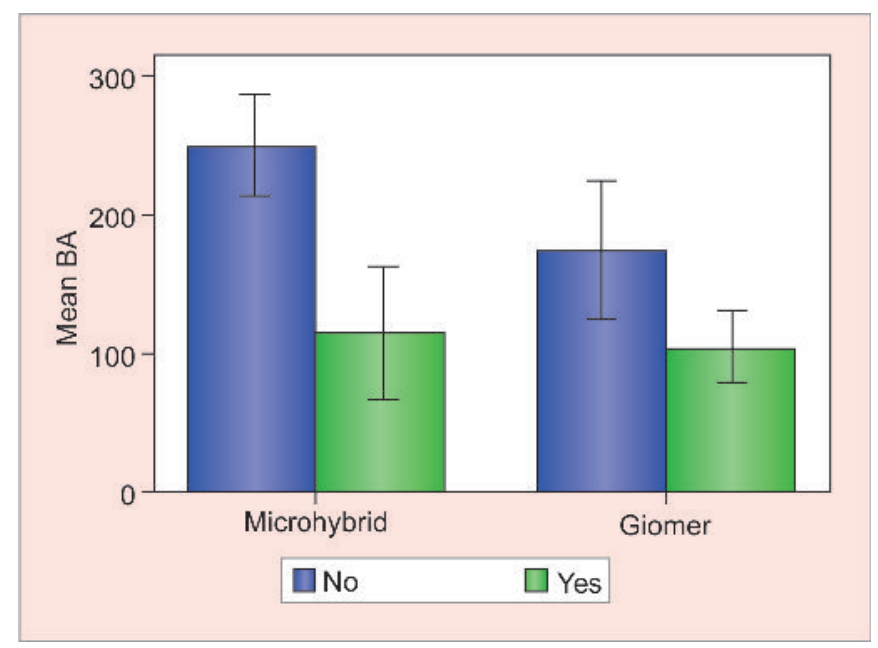

Graph 3: Mean BA based on the restorative materials of this study

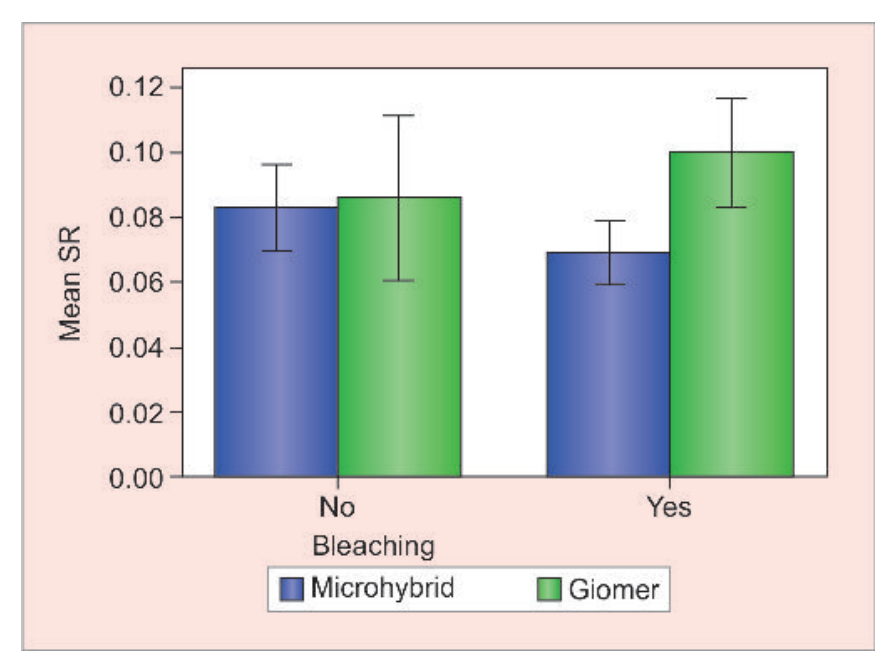

Graph 2: Mean SR of the restorative materials in this study based on bleaching procedure

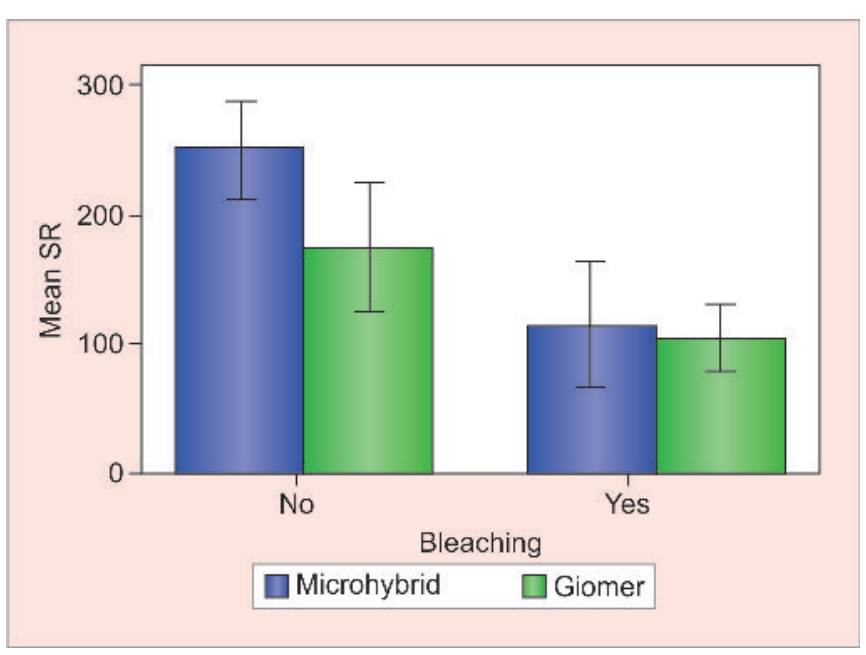

Graph 4: Mean BA based on bleaching procedure in restorative materials of this study 


\section{DISCUSSION}

The prognosis and longevity of restorations depend on the physical, biologic, and mechanical properties of restorative materials. The SR is one of the properties affecting the esthetic appearance, hygiene, plaque retention, and health of the gingival tissue adjacent to composite resin restorations. An increase in SR results in an increase in accumulation of food debris, formation of biofilm, and finally induction of periodontal diseases. ${ }^{28}$ Adhesion of the bacteria to the surface of composite resin and other restorative materials is a factor involved in the etiology of recurrent caries. ${ }^{4}$ Adhesion of bacteria to rough surfaces in the oral cavity is mediated by different mechanisms, involving the type of the bacterial species and the surface itself. ${ }^{29}$

The results of the present study refuted the first hypothesis of the study and showed that the type of the restorative material significantly affected the surface hardness, and giomer samples exhibited more SR. In the present study, a profilometer was used to determine $\mathrm{SR}$, which is an accurate and appropriate technique. In the majority of studies, this instrument has been used to determine SR. ${ }^{30,31}$ Based on a report by Chung, when the SR is $<1 \mu \mathrm{m}$, the surface is smooth visually. The size of the fillers is one of the factors that determines the SR and polishability of restorative materials. ${ }^{30} \mathrm{~A}$ large size of the particles in composite resins might increase microporosities in its structure. Polishing of composite resins is determined based on the longest diameter of fillers. ${ }^{30}$ Composite reins with larger particles tend to exhibit more roughness when they are exposed to abrasive agents and abrasion resulting from foods and drinks. ${ }^{7}$

The two materials evaluated in the present study consisted of Filtek Z250 microhybrid composite resin and Beautifil II giomer. Filtek Z250 microhybrid composite resin has a matrix resin of bisphenol A (Bis) glycol dimethacrylate (GMA), Bis-ethoxylated dimethacrylate, and urethane dimethacrylate, with a filler size of 0.1 to $3.5 \mu \mathrm{m}$. Its filler content is up to $60 \%$ of its volume. Beautiful II is a giomer composite with a matrix of Bis-GMA, triethylene glycoldimethacrylate, with a filler size of 10 to $20 \mu \mathrm{m}$ and particles larger than $4 \mu \mathrm{m}$. Its filler content is up to $68.6 \%$ of its volume. The filler sizes of both materials show that both materials have high polishability and preserve their polish for a long time. However, giomer has fillers with a matrix of glass-ionomer, and this matrix has a large amount of fluoride and metallic ions, and water can easily penetrate into it. ${ }^{16}$ Sorption of water results in the loss of particles a decrease in surface integrity, and a decrease in microhardness. ${ }^{31}$ A higher SR of giomer might be attributed to greater hydrolytic changes in it, resulting in the softening of its matrix.
In relation to the effect of bleaching on SR, it was shown that microhybrid composite resins that did not undergo bleaching, and giomer samples that were bleached exhibited greater SR; however, the differences were not significant. There is controversy in the previous studies over the effect of bleaching on SR of dental materials. Some studies have reported no changes in SR of the restorative materials after bleaching. ${ }^{20,21,23,31-33}$ Some others have reported decreases ${ }^{14,16}$ and some increases $^{22-27,34}$ in SR.

Basting attributed the discrepancies in the results of SR of composite resins after bleaching to the chemical composition of composite reins and the combination of techniques and materials used for bleaching procedures. $^{35}$

In general, factors that have been reported by previous studies as reasons for increases in SR can be summarized as follows. The effect of free radicals on filler matrix interface and debonding of filler (loss of adhesion between the organic and inorganic matrix) result in the formation of microscopic cracks on the surface that can result in SR:25,27,30 Effect of different bleaching gels depends on the oxidation process which occurs in the organic matrix, facilitating sorption of water and resulting in the loss of particles, in a decrease in surface integrity, and in an increase in microhardness. ${ }^{30}$ Hydrogen peroxide attacks the matrix and results in the softening of materials, leading to the loss of glass. In addition, light, too, can increase the effect of hydrogen peroxide on increasing SR. ${ }^{31}$ Munteanu, too, attributed the increase in SR to oxidation and destruction of the resin matrix, which result in further loss of the matrix compared with the inorganic phase. Some other researchers believe that the matrix of composite resins is more resistant to mechanical and chemical challenges and attribute the surface hardness to hydrolytic changes in water, predominantly at the filler matrix interface. ${ }^{25,30}$ Low concentrations of hydrogen peroxide have no significant effect on the surface hardness of composite reins; however, even concentrations higher than those recommended by the manufacturer have no deleterious effects on composite resin surfaces..$^{25}$

El-Murr et al, ${ }^{22}$ too, showed that SR of composite resins increases significantly after bleaching, but since it was $<0.2 \mu$, it was considered clinically important. Attin showed that storage in saliva might decrease the deleterious effects of bleaching by forming a superficial salivary protein layer on the restorative materials. ${ }^{36}$ Mortazavi et $\mathrm{al}^{20}$ showed that SR of microhybrid composite resins does not change after bleaching, which was attributed to the size of fillers in these composite resins that prevent changes in SR even when resin is lost. In the present study, too, bleaching did not increase the SR of giomer and microhybrid composite resin, consistent with the 
results of studies by Mortazavi et al, ${ }^{20}$ Moraes et $a l,{ }^{32}$ and Polydorou et al. ${ }^{33}$ Therefore, the second hypothesis was confirmed.

The results of the present study showed that both the type of the restorative material and bleaching significantly affected BA, with greater adhesion in microhybrid composite resin without any bleaching procedure.

Many factors affect biofilm formation, including SR, free surface energy, and the chemical composition of the surface. ${ }^{37}$ In relation to the surface chemistry, it might be pointed out that release of fluoride from giomer $13,16,27,38,39$ might result in a decrease in microbial adhesion. Some studies have shown that BA of giomer is less than that of other composite resins, which is attributed to the chemical structure of giomer. ${ }^{16,27}$ In fact, giomer has an antibacterial effect, which is related to its fluoride release capacity. ${ }^{13,16,27,38,39}$ It has been shown that specific monomers are released from composite resin that promote the growth of cariogenic bacteria. ${ }^{7}$ Eick et al, ${ }^{40}$ too, showed higher or similar BA of composite resins compared with ceramics and attributed it to the presence of specific monomers or fillers in composite resins that promote BA. In relation to free surface energy, it has been shown that the majority of metallic alloys have antibacterial properties; however, composite resin samples are different from each other. ${ }^{41}$ These studies are consistent with the present study, in which microhybrid composite resin exhibited more BA and giomer exhibited less microbial adhesion.

There is some controversy over the effect of bleaching on BA. The results of the present study showed that bleaching decreased BA. Bleaching might also affect the chemical composition of the surface enamel and restorative materials, changing the adhesion process. ${ }^{29}$ Bleaching might result in a decrease in the adhesion of salivary proteins on the surface of bleached materials through factors containing peroxide, and it appears it might affect the adhesion of cariogenic bacteria, such as S. mutans and S. sobrinus. ${ }^{36}$ Gurgan et $\mathrm{al}^{42}$ reported an antibacterial effect for $10 \%$ carbamide peroxide, consistent with the results of the present study. However, in a study by Montanaro et $\mathrm{al}^{5}$ none of the bleaching agents was able to decrease the number of the microorganisms tested. Some other studies have shown an increase in BA to bleached enamel. ${ }^{17,19,42}$ Mor et $\mathrm{al}^{4}$ showed that $S$. mutans exhibited a stronger adhesion to bleached composite resin surfaces, reporting that bleaching results in some microsurface characteristics on hard surfaces in the oral cavity, paving the way for adhesion of $S$. mutans. Sucrose was used in that study, which has an important role in the adhesion of $S$. mutans. In the present study, saliva was used, which has a protective role for bleached surfaces. ${ }^{31}$ Therefore, it might be pointed out that in the present study, the lower rate of adhesion to giomer surfaces was due to the release of fluoride from giomer and its antibacterial effect. In relation to bleaching, too, lower adhesion might be attributed to the antibacterial properties of $10 \%$ carbamide peroxide, use of artificial saliva, and no use of sucrose. Therefore, the third hypothesis was confirmed.

In the present study, based on Spearman's correlation coefficient, there was no correlation between BA and SR. In the previous studies, surface properties have been reported to be an important factor for BA. ${ }^{14}$ In relation to $S$. mutans, which has the strongest relationship with recurrent caries, ${ }^{6}$ adhesion is first initiated by electrostatic bonds, followed by the activation of extracellular enzymes, such as glycosyl transferase. ${ }^{29}$ Studies have shown that the initial colonization of bacteria begins at surface irregularities, where the bacteria are protected against sheering forces. It has also been demonstrated that restorations with SR promote adhesion of glucans and bacterial colonization. ${ }^{30}$ Yamauchi et $\mathrm{al}^{14}$ showed that the effect of SR on BA depends on the type of the bacterial species. For example, S. mutans exhibited better adhesion to smooth surfaces; however, Porphyromonas gingivalis exhibits better adhesion to rough surfaces. Mei et $\mathrm{al}^{43}$ showed that $S$. mutans adheres to rough surfaces less tenaciously and adhesion of $S$. mutans to composite resin is affected by SR to a lower degree compared with Streptococcus sanguis.

Some studies have shown an increase in BA with an increase in SR. ${ }^{16,18,19,27}$ Some other studies have shown no relationship between SR and BA. ${ }^{17,18,41}$ Rosentritt et al ${ }^{41}$ showed no correlation between SR and BA, reporting an SR value of $<0.08 \mu$ in all the samples. The acceptable threshold of SR is believed to be $0.2 \mu$ and if restorative materials have SR higher than the threshold, there will be an increased risk of plaque accumulation, gingival inflammation, and dental caries. ${ }^{30,44}$ Yamamoto et al ${ }^{15}$ showed no relationship between SR and BA. Since restorative materials are polished very well, differences in BA are due to the properties and chemical composition of materials, consistent with the results of the present study. Therefore, the fourth hypothesis was refuted.

The results of the present study showed that since the currently available composite resins have high polishability, there will be no major changes in the SR after bleaching. In addition, since a threshold of $0.2 \mu$ should be considered for SR for BA, it might be concluded that SR will have no effect on BA. However, further studies are recommended to evaluate the following: (1) The relationship between hydrophilic changes in giomer and its SR; (2) The effect of bleaching on BA in the oral cavity. 


\section{CONCLUSION}

It was concluded based on the results of the present study as follows:

- The type of the restorative material had a significant effect on SR and Ra was higher in giomer; however, bleaching had no effect on SR

- Both the types of the restorative materials and bleaching procedure had significant effects on BA. Bleaching decreased adhesion of $S$. mutans to both materials. Giomer exhibited less BA compared with microhybrid composite resin. In general, microhybrid composite resins without bleaching exhibited greater BA

- Based on the results of Pearson's correlation coefficient, there was no correlation between BA and SR.

\section{REFERENCES}

1. Bahari M, Savadi Oskoee S, Mohammadi N, Ebrahimi Chaharom ME, Godrati M, Savadi Oskoee A. Effect of different bleaching strategies on microhardness of a silorane-based composite resin. J Dent Res Dent Clin Dent Prospects 2016 Fall;10(4):213-219.

2. Parreiras SO, Vianna $\mathrm{P}$, Kossatz $\mathrm{S}$, Loguercio AD, Reis A. Effects of light activated in-office bleaching on permeability, microhardness, and mineral content of enamel. Oper Dent 2014 Sep-Oct;39(5):E225-E230.

3. AlQahtani MQ. The effect of a $10 \%$ carbamide peroxide bleaching agent on the microhardness of four types of direct resin-based restorative materials. Oper Dent 2013 MayJun;38(3):316-323.

4. Mor C, Steinberg D, Doqan H, Rotstein I. Bacterial adherence to bleached surfaces of composite resin in vitro. Oral Surg Oral Med Oral Pathol Oral Radiol Endod 1998 Nov;86(5):585-586.

5. Montanaro L, Campoccia D, Rizzi S, Donati ME, Breschi L, Prati C, Arciola CR. Evaluation of bacterial adhesion of Streptococcus mutans on dental restorative materials. Biomaterials 2004 Aug;25(18):4457-4463.

6. Stenudd C, Nordlund A, Ryberg M, Johansson I, Källestål C, Strömberg N. The association of bacterial adhesion with dental caries. J Dent Res 2001 Nov;80(11):2005-2010.

7. Hilton, TJ.; Ferracane, JL.; Broom, JC. Summitt's fundamentals of operative dentistry. 14th ed. Hanover Park (IL): Quintessence Publishing Co. Inc.; 2013. p. 249-252, 414.

8. Sensi LG, Strassler HE, Webely W. Direct composite resins. Inside Dent 2007;3(7):76-79.

9. Tanthanuch S, Kukiattrakoon B, Siriporananon C, Ornprasert N, Mettasitthikorn W, Likhitpreeda S, Waewsanga $S$. The effect of different beverages on surface hardness of nanohybrid resin composite and giomer. J Conserv Dent 2014 May;17(3):261-215.

10. Heyman, HO.; Swift, EJ.; Ritter, AV. Sturdevant's art and science of oprrative dentistry. 6th ed. Ch. 18. Canada: Mosby; 2013. p. e71.

11. Arora V, Bogra P. Giomer ac a new hbrid aesthetic restorative material. J Conserv Dent 2002 Oct-Dec;5(4):149-155.

12. Naoum S, O'Regan J, Ellakwa A, Benkhart R, Swain M, Martin $\mathrm{E}$. The effect of repeated fluoride recharge and storage media on bond durability of fluoride rechargeable giomer bonding agent. Aust Dent J 2012 Jun;57(2):178-183.
13. Griffin JD Jr. Esthetics, caries control and gingival health with a versatile giomer composite system. Cosmet Dent 2012;1(2):32-36.

14. Yamauchi M, Yamamoto K, Wakabayashi M, Kawano J. In vitro adherence of microorganisms to denture base resin with different surface texture. Dent Mater J 1990 Jun;9(1):19-24.

15. Yamamoto K, Noda H, Kimura K. Adherence of oral streptococci to composite resin restorative materials. J Dent 1989 Oct;17(5):225-229.

16. Kimyai S, Lotfipour F, Pourabbas R, Sadr A, Nikazar S, Milani M. Effects of two prophylaxis methods on adherence of Streptococcus mutans to microfiled composite resin and giomer surfaces. Med Oral Patol Oral Cir Buccal 2011 Jul;16(4):e561-e567.

17. Hosoya N, Honda $K$, Iino $F$, Arai T. Changes in enamel surface roughness and adhesion of Streptococcus mutans to enamel after vital bleaching. J Dent 2003 Nov;31(8):543-548.

18. Güorgan S, Bolay S, Alaçam R. In vitro adherence of bacteria to bleached or unbleached enamel surfaces. J Oral Rehabil 1997 Aug;24(8):624-627.

19. OskoeeSS, OskoeePA, Soroush MH, Ajami AA, Behestirouy M, Pournaghi-Azar F. Effect of 10\% sodium ascorbate on Streptococcus mutans adherence to bleached bovine enamel surface. Afr J Biotechol 2010 Aug;9(33):5419-5422.

20. Mortazavi V, Fathi MH, Shirian MR. Effect of bleaching on surface roughness of two nanofilled and a microhybrid composite. J Isfahan Dent Sch 2008;3(4):195-205.

21. Zuryati AG, Qian OQ, Dasmawati M. Effects of home bleaching on surface hardness and surface roughness of an experimental nanocomposite. J Conserv Dent 2013 Jul;16(4): 356-361.

22. El-Murr J, Ruel D, St-Georges AJ. Effects of external bleaching on restorative materials: a review. J Can Dent Assoc 2011 May;77:b59.

23. Turker SB, Biskin T. Effect of three bleaching agents on the surface properties of three different esthetic restorative materials. J Prosthet Dent 2003 May;89(5):466-473.

24. Alqahtani MQ. Tooth-bleaching procedures and their controversial effects: a literature review. Saudi Dent J 2014 Apr;26(2):33-46.

25. Munteanu BO, Andrian SO, Iovan GI, Ghiorghe AN, Nica I, Stoleriu S. Influence of different bleaching agents on surface roughness of composite resins filling. Mater Plast 2014 Jun;51(3):279-281.

26. Cengiz E, Kurtulmus-Yilmaz S, Ulusoy N, Deniz ST. The effect of home bleaching agents on the surface roughness of five different composite resins: a SEM evaluation. J Scan Microsc 2016 May;38(3):277-283.

27. Mohammadi N, Kimiyai S, Abed-Kahnamoii M, EbrahimiChaharom ME, Sadr A, Daneshi M. Effect of $15 \%$ carbamide peroxide bleaching gel on color stablity of giomer and microfield composite resin: an in vitro comparison. Med Oral Pathol Oral Cir Bucal 2012 Nov;1(17):e1089-e1098.

28. Sofi LR, Khamverdi Z, Kasraei S, Vahdatinia F, Nasr F. The effect of hydrogen peroxide $35 \%$ on surface roughness of silorane and methacrylate based composites. Sci J Hamadan Univ Med Sci 2015;22(1):23-29.

29. ShahalY,Steinberg D, HirschfeldZ, BronshteynM,KopolovicK. In vitro bacterial adherence onto pellicle-coated aesthetic restorative materials. J Oral Rehabil 1998 Jan;25(1):52-58.

30. Vishwakarma P, Karale R, Srirekha A, Hegde J, Savitha B, Srinivasan A. The effect of home bleaching agents on the 
surface roughness and fracture toughness of composite resin materials. Dentistry 2014 Jun;4:246.

31. Wang L, Francisconi LF, Atta MT, Dos Santos JR, Del Padre NC, Gonini A Jr, Fernandes KB. Effect of bleaching gels on surface roughness of nanofilled composite resins. Eur J Dent 2011 Apr;5(2):173-179.

32. Moraes RR, Marimon JL, Schneider LF, Correr Sobrinho L, Camacho GB, Bueno M. Carbamide peroxide bleaching agents: Effects on surface roughness of enamel, composite and porcelain. Clin Oral Investig 2006 Mar;10(1):23-28.

33. Polydorou O, Hellwig E, Auschill TM. The effect of different bleaching agents on the surface texture of restorative materials. Oper Dent 2006 Jul-Aug;31(4):473-480.

34. Campos I, Briso AL, Pimenta LA, Ambrosano G. Effects of bleaching with carbamide peroxide gels on microhardness of restoration materials. J Esthet Restor Dent 2003 May;15(3): 175-182.

35. Basting RT, Fernandéz Y Fernandez C, Ambrosano GM, de Campos IT. Effects of a $10 \%$ carbamide peroxide bleaching agent on roughness and microhardness of packable composite resins. J Esthet Restor Dent 2005 Jul;17(4):256-262.

36. Attin T, Hannig C, Wiegand A, Attin R. Effect of bleaching on restorative materials and restorations - a systematic review. Dent Mater 2004 Nov;20(9):852-861.

37. Merta U, Wiśniewska G. Bacterial adhesion to dental materials - a literature review. Dent Forum 2015;41(1):65-67.
38. Tarasingh P, Reddy JS, Suhasini K, Hemachandrika I. Comparative evaluation of antimicrobial efficacy of resinmodified glass ionomers, compomers and giomers - an in vitro study. J Clin Diagn Res 2015 Jul;9(7):ZC85-ZC87.

39. Hotwani K, Thosar N, Baliga S, Bundale S, Sharma K. Antibacterial effects of hybrid tooth colored restorative materials against Streptococcus mutans: an in vitro analysis. J Conserv Dent 2013 Jul;16(4):319-322.

40. Eick S, Glockmann E, Brandl B, Pfister W. Adherence of Streptococcus mutans to various restorative materials in a continuous flow system. J Oral Rehabil 2004 Mar;31(3): 278-285.

41. Rosentritt M, Hahnel S, Gröger G, Mühlfriedel B, Bürgers R, Handel G. Adhesion of Streptococcus mutans to various dental materials in a laminar flow chamber system. J Biomed Mater Res B Appl Biomater 2008 Jul;86(1):36-44.

42. Gurgan S, Bolay S, Alaçam R. Antibacterial activity of 10\% carbamide peroxide bleaching agents. J Endod 1996 Jul;22(7):356-357.

43. Mei L, Busscher HJ, van der Mei HC, Ren Y. Influence of surface roughness on streptococcal adhesion forces to composite resins. Dent Mater 2011 Aug;27(8):770-778.

44. Sakaguchi, RL.; Powers, JM. Craig's restoration dental materials. 13th ed. New York: Quintessence Publishing, Elsevier, Mosby; 2012. p. 18. 